This item was submitted to Loughborough's Research Repository by the author.

Items in Figshare are protected by copyright, with all rights reserved, unless otherwise indicated.

\title{
Formulating solutions in mediation
}

PLEASE CITE THE PUBLISHED VERSION

http://dx.doi.org/10.1016/j.pragma.2016.08.006

\section{PUBLISHER}

(c) Elsevier

VERSION

AM (Accepted Manuscript)

\section{PUBLISHER STATEMENT}

This work is made available according to the conditions of the Creative Commons Attribution-NonCommercialNoDerivatives 4.0 International (CC BY-NC-ND 4.0) licence. Full details of this licence are available at: https://creativecommons.org/licenses/by-nc-nd/4.0/

\section{LICENCE}

CC BY-NC-ND 4.0

\section{REPOSITORY RECORD}

Stokoe, Elizabeth, and Rein O. Sikveland. 2019. "Formulating Solutions in Mediation". figshare. https://hdl.handle.net/2134/20080. 


\title{
Formulating solutions in mediation
}

\author{
Elizabeth Stokoe and Rein O. Sikveland \\ Department of Social Sciences \\ Loughborough University \\ Ashby Road \\ Loughborough \\ LE11 3TU
}

Accepted for publication in Journal of Pragmatics, Jan 2016, special issue on 'formulations' edited by Fleur van der Houwen and Keun Young Sliedrecht 


\section{ABSTRACT}

This paper examines the work done by formulations in the service of pursuing solutions to disputes between neighbours in a community mediation setting. In particular, it shows how mediators formulate the talk of mediation clients - the parties in dispute - in a particular sequence of activities. Parties' complaints are formulated by the mediator, often proposing common ground between them. Mediators ask 'solution-focused questions' (SFQs), which are treated in mediation training as a key method for effecting client-generated solutions to neighbour disputes. Drawing on a collection of 30 recorded mediation sessions between mediators and their clients, conversation analysis shows how formulations do more than (or do not necessarily) 'summarize' what clients have said. Rather, they do institutional work of various kinds, including reconstructing clients' versions of events and initiating sequences in which decisions about change are accomplished. In other words, formulations are at the heart of the mediation process, in which mediators attempt to scaffold clients to come to an agreement about ways to move forward, without giving direct instruction or advice.

\section{KEYWORDS}

Mediation; Formulations; Applied Conversation Analysis; Solution-focused questions; Dispute

\section{INTRODUCTION}

Mediation is a method of conflict resolution, often positioned as an alternative to courts and legal processes, through which people involved in a dispute attempt to resolve their differences. Mediators act as impartial third parties and aim to guide parties to bring about their own solutions. When clients come to mediation, their complaints and experiences are routinely summarized, or formulated, by the mediator. The paper examines a particular practice in mediation in which such formulations co-occur with questions that seek to get clients to make suggestions about ways out of the conflict. These questions are commonly referred to as 'solution-focused questions' (SFQs). We focus particularly on a sequence identified in both individual meetings (in which mediators talk to disputing parties individually) and 'round table' sessions (where both parties are present) in which mediators 1) produce formulations: summaries that proffer the mediator's candidate understanding of what the clients have said about the problem (Heritage and Watson, 1979), and then 2) produce SFQs. We will see how formulations work to progress the mediation from sequences of 
problem description and troubles tellings to the work of mediation: finding solutions to the dispute.

Let us start with a brief example of the sequence we examine in our subsequent analysis. In Extract 1, two parties, Deb and Terry, are in mediation with two mediators (M1 and M2). Their dispute is about noise: Terry has complained that he "can't get a good night's sleep" and we join the mediation as Deb describes what she has done to try to be quieter.

\section{Extract 1: NM-C252RT2}

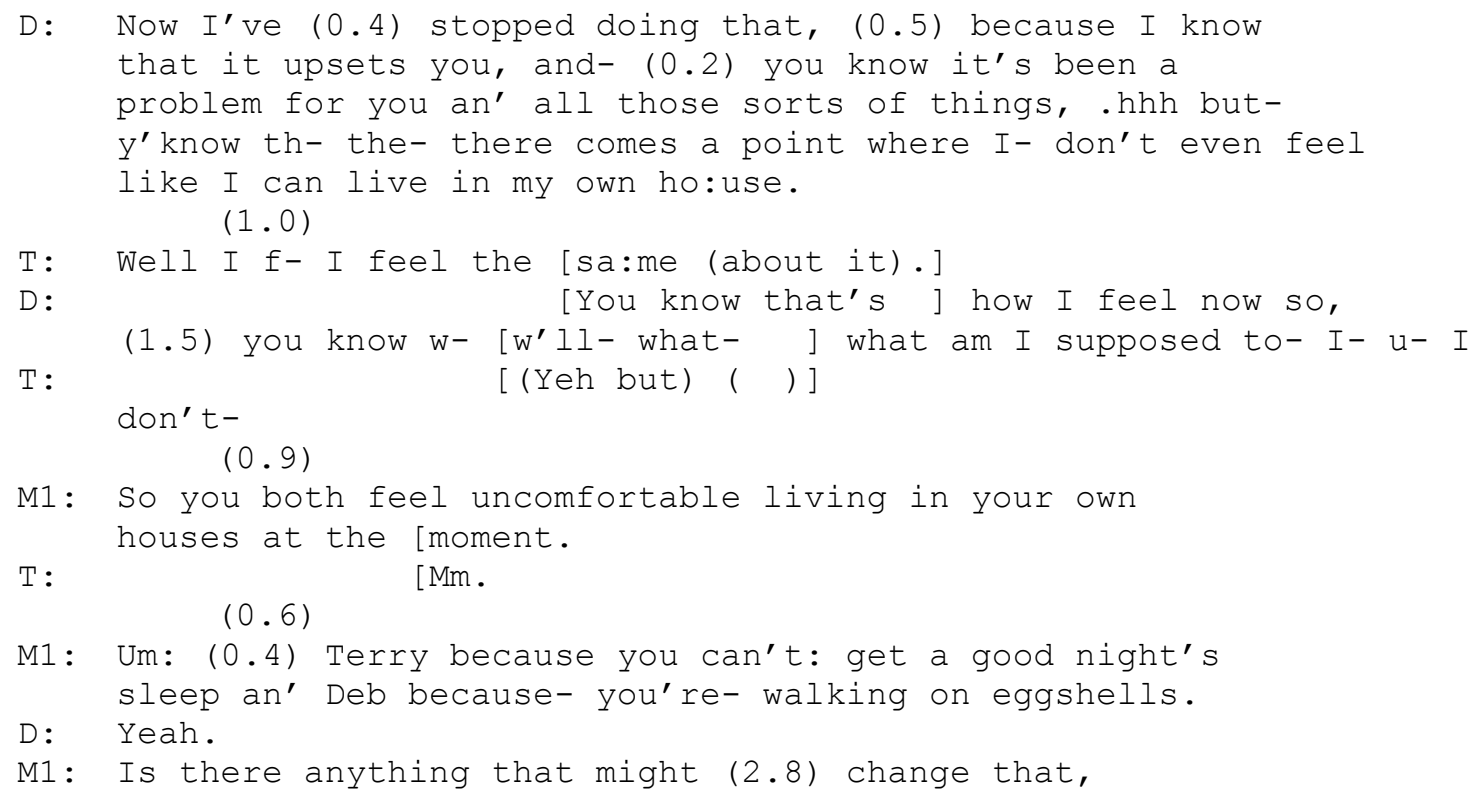

Our focus is on M1's summary formulation ("So you both feel...", lines 1-6) of the clients' perspectives on their noise dispute (lines 13-14), followed by an SFQ ("Is there anything that might (2.8) change that,", line 20). M1's summary "involves summarizing, glossing, and developing the gist of the informant's earlier statements" (Heritage and Watson, 1979: 100). Formulations such as these work frequently to provide the gist or upshot of previous talk. As Bolden (2010:8) points out, "such formulations are sequence-initiating actions: they function as requests for confirmation, making a response (a confirmation or disconfirmation) conditionally relevant from the addressee". M1 therefore makes a 'recipient formulation', one which is "commonly used by an institutional agent (such as, a therapist or an interviewer) to reformulate and operate on the layperson's (e.g. a client's or an interviewee's) words" (ibid.). Note that M1 is not formulating a stance toward the dispute to which she has primary epistemic access, but rather one which summarizes the stances of the clients, who each have primary access to their own stances. 
The sequential relationship of the solution-focused question to the formulation is one which we will see repeated in the analysis section. Note also that M1's formulation comes at a point where the clients are simultaneously struggling to formulate a next action and starting to compete for turns (lines 7-11). As such, the formulation achieves two key things. First, as Bolden (2008) notes, it initiates a new sequence precisely at the point where the clients make competitive incursions into each other's turns (note the multiple overlapping turns between lines 7-11; see Wells and MacFarlane, 1998).

Second, it constructs the parties to a dispute as nevertheless having something in common: that they both feel uncomfortable. The formulation is therefore also a place to transform clients' descriptions from individual, one-sided and heavily invested stances towards the dispute, into something two-sided and reciprocal, in order to serve the institutional aims of mediation. Terry (line 15) and Deb (line 19) confirm, minimally, M1's version of their perspectives on the noise dispute, although their confirmations are placed differently: Terry confirms M1's formulation that they "both feel uncomfortable", while Deb confirms M1's unpacking of each side's stance towards the situation.

The data for the current paper come from a large scale qualitative study of neighbour disputes, which examined not just mediation sessions like Extract 1, but also initial telephone queries into mediation services, as well as calls from members of the public to environmental and housing services and police-suspect interrogations about criminal-level neighbour conflict (see Stokoe and Edwards, 2009). While little research on neighbor disputes themselves has been undertaken (see Stokoe, 2006), researchers have engaged in a great deal of work on the management of such disputes, particularly on mediation and its practices. Much of the research has focused on participants' experiences of mediation and their evaluations of mediators and the mediation process, or on mediators' reports about their strategies for (un)successful mediation (e.g., Alberts, Heisterkamp and McPhee, 2005; Goldberg, 2005). For example, Wall, Dunne and Chan-Serafin (2011) noted that a recurrent theme in mediation research has been its focus on mediation styles and strategies, from "evaluative-directive" or "narrative," to "problem-solving" or "understanding-based". Their review also noted extensive research-based advice to mediators for managing the process as well as the behavior of disputing parties (e.g., "be neutral," "evaluate," "improvise," "obtain trust") and they also noted that there has been substantial research focused on outcomes for disputants (e.g., finding agreement), mediators (e.g., indicators of success, continued funding of service) and third parties (e.g., reduced use of court and police resources: see Charkoudian, 2011).

Mediation research has generally been conducted via the collection of self-report data, survey responses, and/or interviews, with little attention paid to tracking the "moment- 
to-moment activities that shape meaning, realities, and outcomes" (Glenn and Susskind, 2010:118). A few studies, however, have examined actual encounters between mediators and clients, showing "how the participants in a negotiation session come together ... helps us understand how negotiation works ... and how to teach and train about the art and practice of negotiation" (ibid.). These studies, like the current paper, examine the live conversations between mediators and clients, their organizational structure, and constituent actions. Analyses attend both to what mediators do, in terms of their techniques and practices, as well as what clients do, in terms of formulating complaints, defenses, and so on (e.g., Greatbatch and Dingwall, 1997; Jacobs and Aakhus, 2002; Trinder, Firth and Jenkins, 2010). To the best of our knowledge, detailed examinations of solution-focused questions have rarely been studied in mediation, though a handful of other studies focus on 'solutionfocused' approaches in therapeutic settings (e.g., Bowles, Mackintosh and Torn, 2001; Gale and Newfield, 1992). In Fitzgerald and Leudar's (2012) study of psychotherapeutic interaction, they focused on how therapists manage to be 'non-directive'. They noted that "therapists who claim to practice non-directive, non-authoritarian therapy nevertheless exercise subtle means of influencing their clients" (p. 13). One way that they did this was through formulations, which they show were "used to guide clients to think along lines conducive to change" (ibid.). Relatedly, van der Houwen's (2009) analysis of formulations focuses on their role in televised small claims disputes, although, unlike the courtroom, the mediators' role is to maintain impartial rather than make judgments.

As we can see in Extract 1, the mediator's formulation sets up a slot for a question directed towards the clients, "Is there anything that might (2.8) change that". The question is central to the work of mediation: facilitating dispute resolutions that come from the clients rather than the mediator. The question is an example of one of the tools of 'solution-focused' practice, which, in turn, originates in 'solution-focused brief therapy' (SFBT) (Molnar and de Shazer, 1987). This approach to therapy is 'goal-directed', and works with the assumption that recognizing that although the history and roots of disputes may be complicated, their solutions can be less so (de Shazer, 1994). Particular sorts of solution-focused questions (SFQs) are central to SFBT and its translation in other contexts, designed to help people explore their strengths and resources rather than concentrate on their problems and deficits.

Overall, then, our paper will contribute to what we know about formulations in institutional practice and their precise role in driving the mediation process as actions that provide for subsequent solutions for mediation clients. 


\section{DATA AND METHOD}

The dataset for this study comprises approximately thirty mediation meetings recorded at five different community mediation services based in the United Kingdom. The process starts with mediators meeting parties individually and then, if all agree, they meet both parties at a 'round table' to try and facilitate a solution. The data were originally collected for a British research council-funded project on neighbor disputes. All participants consented to have their mediation meetings recorded for research purposes; all names and other identifying features of the calls were anonymized. The data were transcribed using Gail Jefferson's (2004) system for conversation analysis (CA). CA examines the macro-organization interaction, in terms of its constituent actions, as well as the specifics of, and patterns in, turn design, turn-taking, action formation, and sequence organization.

Our analysis focuses on the work of formulations in mediation. We trawled our dataset and identified a pattern in their co-occurrence with solution-focused questions (SFQs). Before focusing on this co-occurrence analytically, it is relevant to note that, in training materials used by mediators, SFQs are described as questions that help clients to identify what their goals or preferred future will look like when they have overcome their problems or difficulties (e.g., "How will things be different when the problem is better?"). Other SFQs encourage clients to "Tell me about times when the problem is less troubling". Solution-focused brief therapy also includes a 'miracle question' (e.g., "If you woke up tomorrow, and a miracle happened so that the dispute had gone, what would you see differently?). However, in the empirical materials, SFQs did not echo the training materials in terms of their design. Conversation analysts have regularly shown that, when practitioners attempt to turn training materials or scripted questions into actual interaction, the ensuing practices vary from those idealised versions (e.g., Houtkoop-Steenstra and Antaki, 1997; Maynard and Schaeffer, 2006; Stokoe, 2013). In order to build a collection, then, we identified 'future hypothetical' questions as the closest to idealized SFQs and focus on the way formulations provide a sequential context for their placement in mediations.

The majority of our analysis focuses on representative examples of formulations of clients' complaints or experiences when they are both co-present with the mediator, in 'round table' mediations. We have deliberately included several extracts from the same cases to show that and how formulations and SFQs work iteratively across long encounters to progress to a resolution of the dispute. In addition, we consider an example where a formulation provides the vehicle for asking an SFQ within one turn in an individual party meeting. 


\section{ANALYSIS}

Our analysis identified the following sequence of actions, which we will unpack across the instances reported in the following sections.

a. Formulations are preceded by parties complaining or arguing;

b. The Formulation: Mediators formulate either i) one party's version of, or stance towards, the dispute, or ii) something that both parties share;

c. Clients confirm, reject or disattend the formulation;

d. The SFQ: Mediators ask a 'future hypothetical' question of the client or clients;

e. The response: Either i) mediators themselves provide a candidate answer to their SFQ; or ii) clients provide a candidate solution but, more commonly, complain further;

f. Mediators produce multiple iterations of formulation-SFQ sequences.

Mediations typically last an hour or more, so we will attempt to provide sufficient context for readers to understand the location and sequential organization of the target phenomena in these long encounters.

\subsection{From formulation to $S F Q$}

Formulations of clients' complaints, perspectives and experiences appeared in the mediation sessions, as a key resource for mediators to progress the mediation from one phase to another. Extract 2 comes from an individual meeting (although the interaction is multiparty, not dyadic) in which formulation and subsequent SFQ is combined into one turn. Two mediators are present, and the party is three people: a mother (Susie), her daughter (also called Susie - who does not speak in this extract) and the mother's friend Carla who is there for support. Susie's neighbours have complained about her noisy children. M1 has asked, "What happens if you actually come across each other in the street?" Susie has responded with a story about how she has good relationships with everyone in the street but that this particular neighbour ignores her. Carla concludes the narrative by reporting an incident when they all met in the local pub.

\section{Extract 2: NM-C261P2}

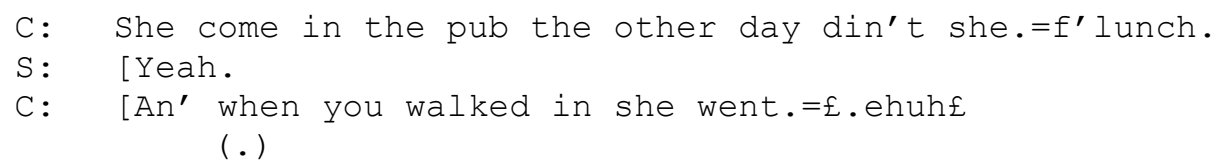




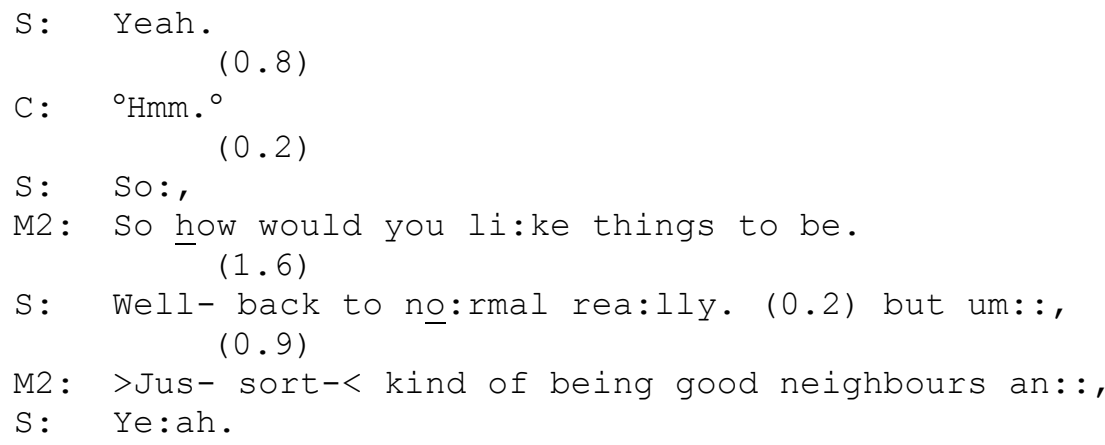

Having come to the end of their response to M1's question, which embeds a complaint about Susie's neighbour, both Susie and M2 take turns that formulate, or start to formulate, some prior or incipient activity. What is interesting about this extract is that while there is no 'textbook' formulation of Susie's version of events (e.g., "so your neighbour ignores you when she sees you"), both S (line 9) and M2 (line 10) move towards a next action with turns initiated by the discourse marker "so". As conversation analysts have pointed out, 'so' also routinely appears in turn initial position in formulation turns (Bolden, 2009). Bolden (2009: 302) notes that, in this position, "so ... serves to characterize the upcoming action as introducing the conversation's first intended topic-something that was projected by the very act of initiating the contact and oriented to by participants as having been pending or incipient". In this case, a solution to the dispute is the reason for the encounter. Susie's "so:,", which is both a stand-alone turn constructional unit and trails off, does not supply an explicit upshot but marks that one might be relevant, which is then picked up by M2. M2's question "So how would you li:ke things to be." is a vehicle for the SFQ - it is a future-oriented hypothetical question, but also formulates the upshot of the reason for their encounter: identifying a path to a different relationship between the neighbours. Similarly, Bolden (2008) finds that "so" appears in turns that move to business in institutional talk of various kinds.

After M2 asks the SFQ, there is a delay (line 11) and then Susie responds with a 'wellprefaced' turn, which conversation analysts have shown "operate as general alerts that indicate non-straightforwardness in responding" (Schegloff and Lerner, 2009: 91). Susie's response is somewhat idiomatic ("back to normal"), but she indicates trouble in unpacking her meaning with the pause and the trail-off "um::," at the end of her turn. After another gap, M2 supplies a candidate analysis of what "back to normal" means (line 14). As we will see, it was typical that mediators provided responses to their own SFQs, as a way of working towards a solution without providing advice directly, something which they are mandated not to do (see Weatherall, 2015).

In Extract 3, we return to the session we first encountered in the Introduction in which both parties and two mediators are present. So far, Terry has complained about Deb's noise 
when he goes to bed. Deb has said she has made "considerable effort to reduce the noise" and this has affected how she lives her life. Terry says that Deb talks too loudly when she gets home from a night out, and does not respect him. Deb says she does respect him. We join the session as Terry concludes the latest iteration of his complaint about Deb.

\section{Extract 3: NM-C252-RT}

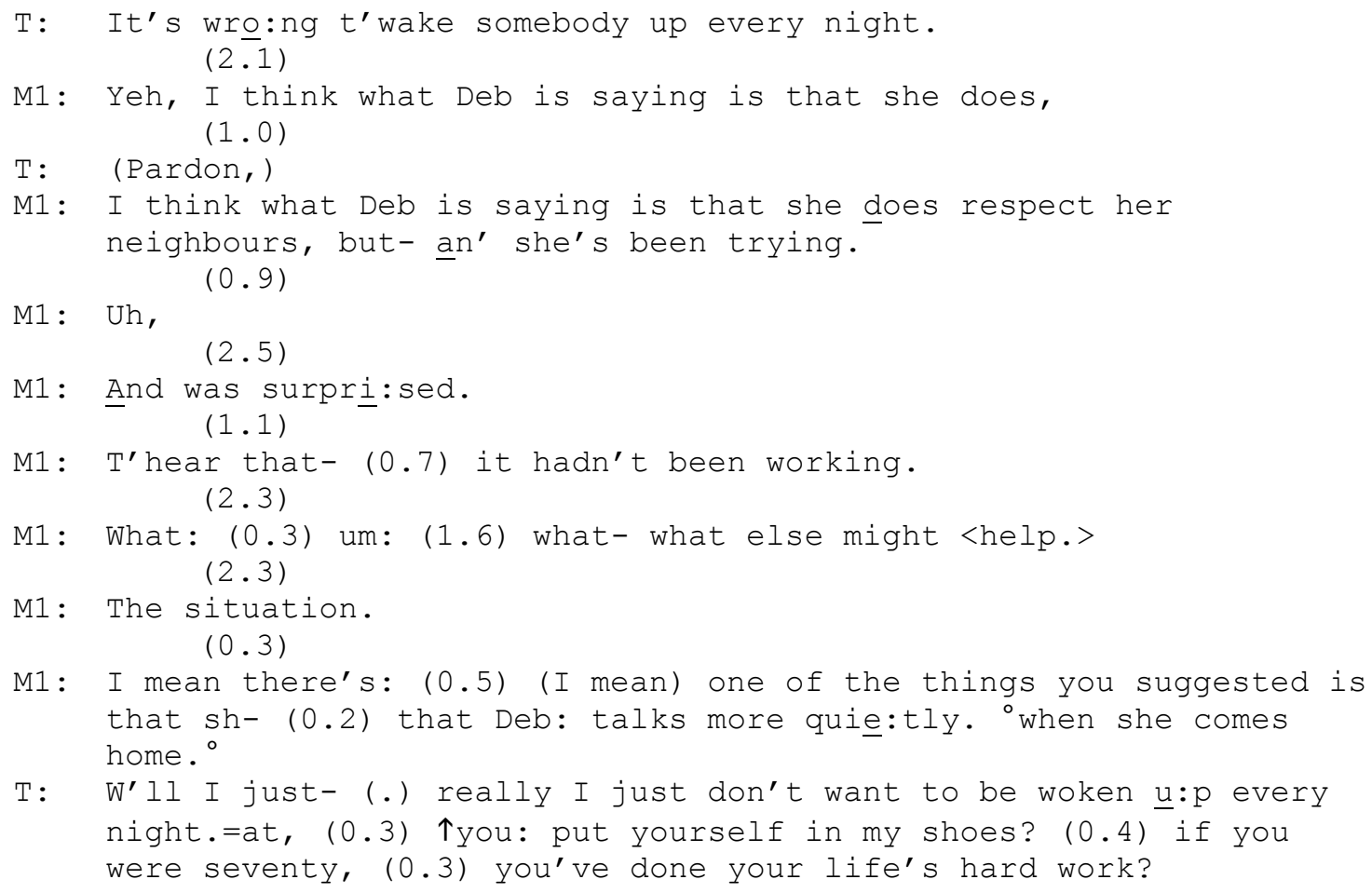

The extract contains the component features of formulation-SFQ sequences described earlier. The target formulations come after a period of complaining by Terry; M1 formulates Deb's version of, or stance towards, the dispute (lines 3-13); neither party confirms the formulation (Terry is the recipient of the formulation, not Deb, lines 5, 8-10, 12, 14); M1 asks a 'future hypothetical' question of the client or clients (lines 15-17); M1 provides a candidate answer to her own SFQ; Terry does not supply a solution but complains further.

In more detail, then, following Terry's complaint that "It's wro:ng t'wake somebody up every night.", M1 begins to formulate Deb's version of events (lines 3-13). Given Heritage and Watson's (1979) observation that the preferred response to a formulation is a confirmation, it is interesting that in mediated, multiparty instances, issues of recipiency are quite different: M1 does not design her formulation of Deb's experience for Deb; Terry does treat M1's formulation as something she should respond to.

It seems that Terry might not have heard the first part of M1's formulation, as he issues a repair initiator (line 5), and M1 restarts her formulation at line 6 . Note that this formulation 
is not two-sided; she formulates only Deb's stance towards the dispute rather than both. In this way, it is hearable that M1 is less than impartial at this point in the mediation: in response to Terry's complaint, M1 provides a counter to it by formulating Deb's side of the dispute, rather than waiting for Deb to respond for herself. This is in contrast to, say, Heritage's (1985) analysis of formulations in news interviews, in which formulations function to minimally invite recipients to confirm or deny. Heritage also shows that news interviewers use formulations to evaluate or criticize the recipient's remarks, repackage their remarks for the overhearing audience, or reformulate in stronger or more combative terms what the interviewee said. While we will see that formulations provide mediators with opportunities to construct versions of clients' prior talk, they are different in quality to news interviewers'.

At line 15, M1 issues the SFQ: "What: (0.3) um: (1.6) what- what else might <help.>". After receiving no response from either party, she pursues one by adding an increment (line 17) and then begins to offer a candidate answer herself (lines 19-21). Here, she formulates ("one of the things you suggested") Terry's earlier suggestion that "Deb: talks more quie:tly. 'when she comes home.". However, Terry does not confirm M1's formulation of his earlier suggestion but reinstates his complaint (lines 22-24). This is a pattern that is repeated across the session.

In Extract 4, which is an extended version of Extract 1, we rejoin the mediation as Deb describes how she feels about their dispute.

\section{Extract 4: NM-C252-RT}

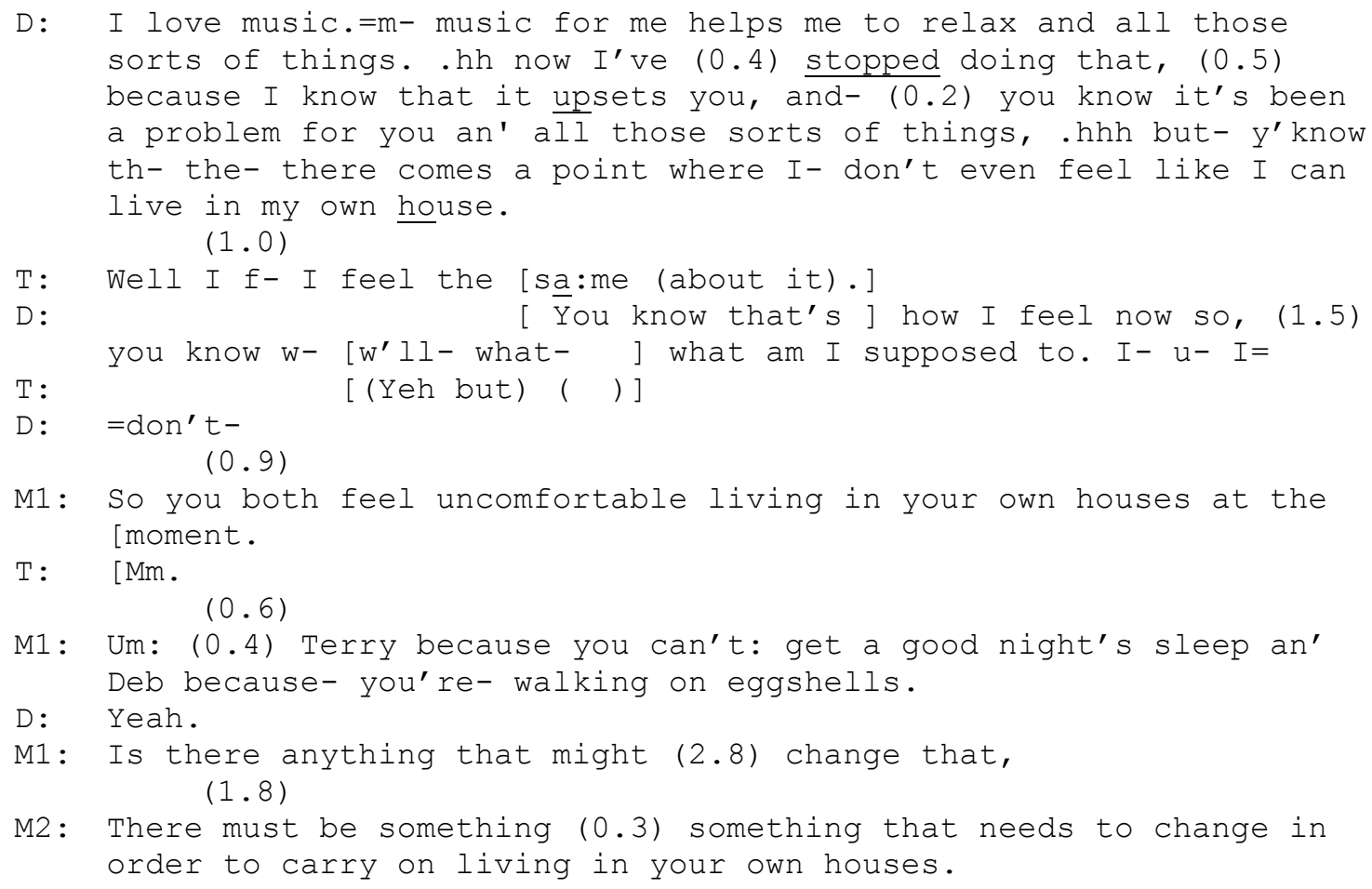


25 T: But I just- I just can't get a night's sleep.=I mean (0.3) it's:

$26(0.3)$ simple as that.

Like the previous extracts, the mediator's formulation comes after a period of complaining and, in this case, an argument between clients about their feelings towards the situation (lines 8-12). After a gap (line 13), M1 produces the target formulation. In contrast to Extract 3 , M1 formulates both parties' issues ("So you both feel uncomfortable..."). The formulation works to formulate as shared between parties their discomfort as a basis for moving forward (see Van der Houwen, 2009, on 'bridging formulations' in small claims courts). While Terry has said that he "can't get a good night's sleep" on multiple occasions previously, making M1's formulation close to his way of expressing his concerns, she (re)formulates Deb's words using the idiomatic phrase "walking on eggshells" (line 19). Terry confirms, minimally, that they are both uncomfortable (line 16) and Deb confirms that she is "walking on eggshells" (line 20).

At line 21, M1 asks a solution-focused question, "Is there anything that might (2.8) change that,". By seeking solutions from the clients, M1 retains the impartial, non-directive stance of the mediator. However, no response is forthcoming at line 22; in fact, there is a long gap of 1.8 seconds. M2 takes the next turn, his response providing an analysis of the gap and a possible problem in M1's turn. His attempt to get the clients to talk is formatted as a declarative statement that "something needs to change" (lines 23-24). Interestingly, M2's alternative method of getting clients to talk (which they do, next) provides support for Heritage and Robinson's (2007) finding that questions with the word 'any' in them, in contrast to those designed with the word 'some', typically do not generate a positive response in the context of doctors trying to elicit from patients reasons for their visit. Here, M2's proposal that 'something' needs to change does generate a response; however, it is not a solution but further reinstating of the complaint by Terry. And by doing so he resists the terms of the mediator's question. This continues for a further ten lines, at which point we rejoin the mediation in Extract 5.

\section{Extract 5: NM-C252-RT}

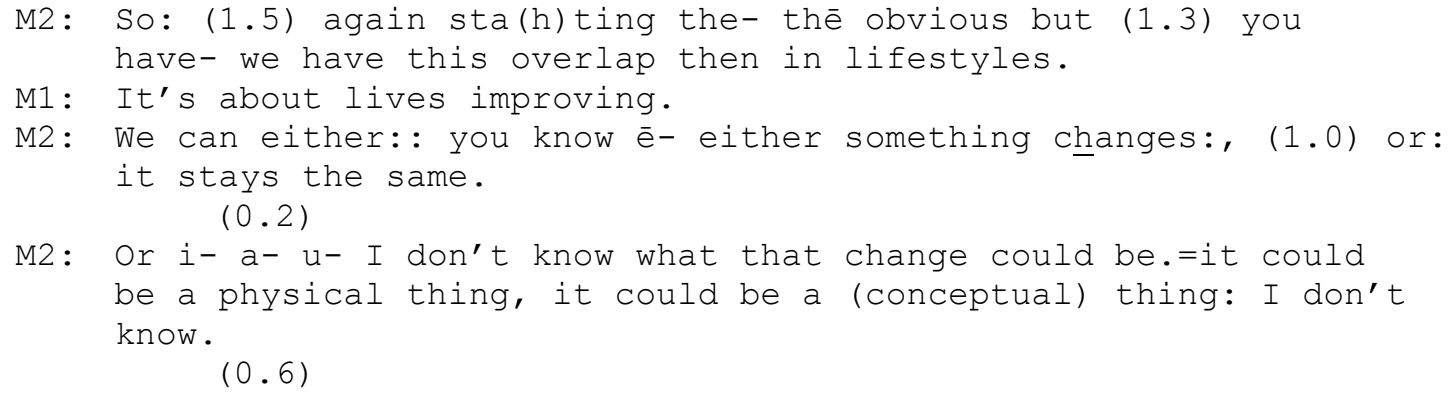




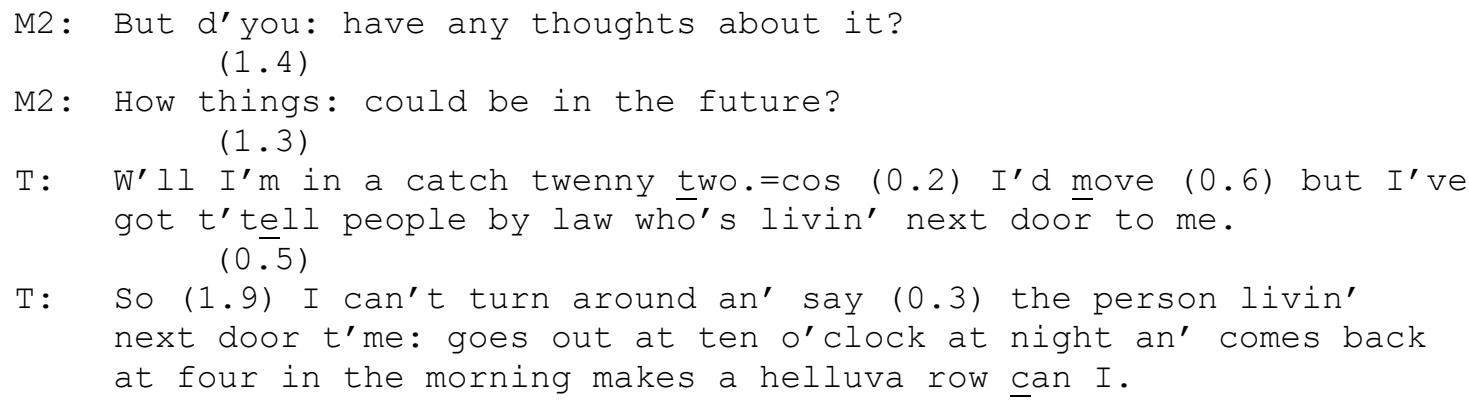

The iterative nature of formulations and SFQs is oriented to in M2's first formulation of the parties' stances: he notes that they are here 'again' and that he 'states the obvious' (lines 36-7). The extract contains the same component actions seen earlier: the formulation is preceded by complaining; M2 formulates the parties' problem as reciprocal and shared rather than as two distinct issues ("You have- we have this overlap then in lifestyles", line 37). The self-repair, from 'you have' to 'we have' works to produce the mediation as a collaborative enterprise between the clients and the mediators. At this point, M2 has not asked a question but uttered a declarative formulation which is not confirmed by either party. M2 takes the next turn, adding another declarative which formulates the upshot of the mediation process (line 38), and then M2 adds a further declarative statement to summarize 'where things stand' ("either something changes:, (1.0) or: it stays the same."). Neither client appears to treat these formulations as requiring confirmation (lines 41,45 ).

Like previous extracts, M2 provides a candidate answer to the clients' problems in terms of what could change ("it could be a physical thing, it could be a (conceptual) thing:"), but this precedes the SFQ rather than follows it. The "I don't knows" that preface and end his list work to construct M2 as having no stake in any particular solution that the clients may come up with (Edwards, 1995). In this way, M2 manages to introduce possible solutions without favouring any of them. Although we do not know, without video, if M2 selected one of the clients to respond, it seems as though neither responds and so M2 asks a direct question "d'you: have any thoughts about it?" (line 46). Given the context, of course, answering such questions 'first' might be treated as admitting fault. Like Extract 4, the 'any' design of the question does not elicit a response from the clients. After a long gap (line 47), like the mediator in Extract 4, M2 pursues a response with an increment (line 48). After another gap, and like previous extracts, Terry does not provide a solution, but explains how there is no solution ("I'm in a catch twenny two") and takes the opportunity to yet again reinstate his complaint about Deb, this time with an account for why a solution is not possible (lines 50-55).

We can see, across the previous three extracts, how formulations and SFQs work iteratively to drive the mediation forward. Mediators formulate the different parties versions of 
events, including what they share, and follow it with an SFQ in an attempt to elicit from clients the makings of a solution. However, as we have seen, while SFQs are designed to effect solutions, a common response is to resist the presupposition of the question and continue to complain about the other party. We rejoin the session a few minutes later, with another iteration of Terry's complaint about Deb.

\section{Extract 6: NM-C252-RT}

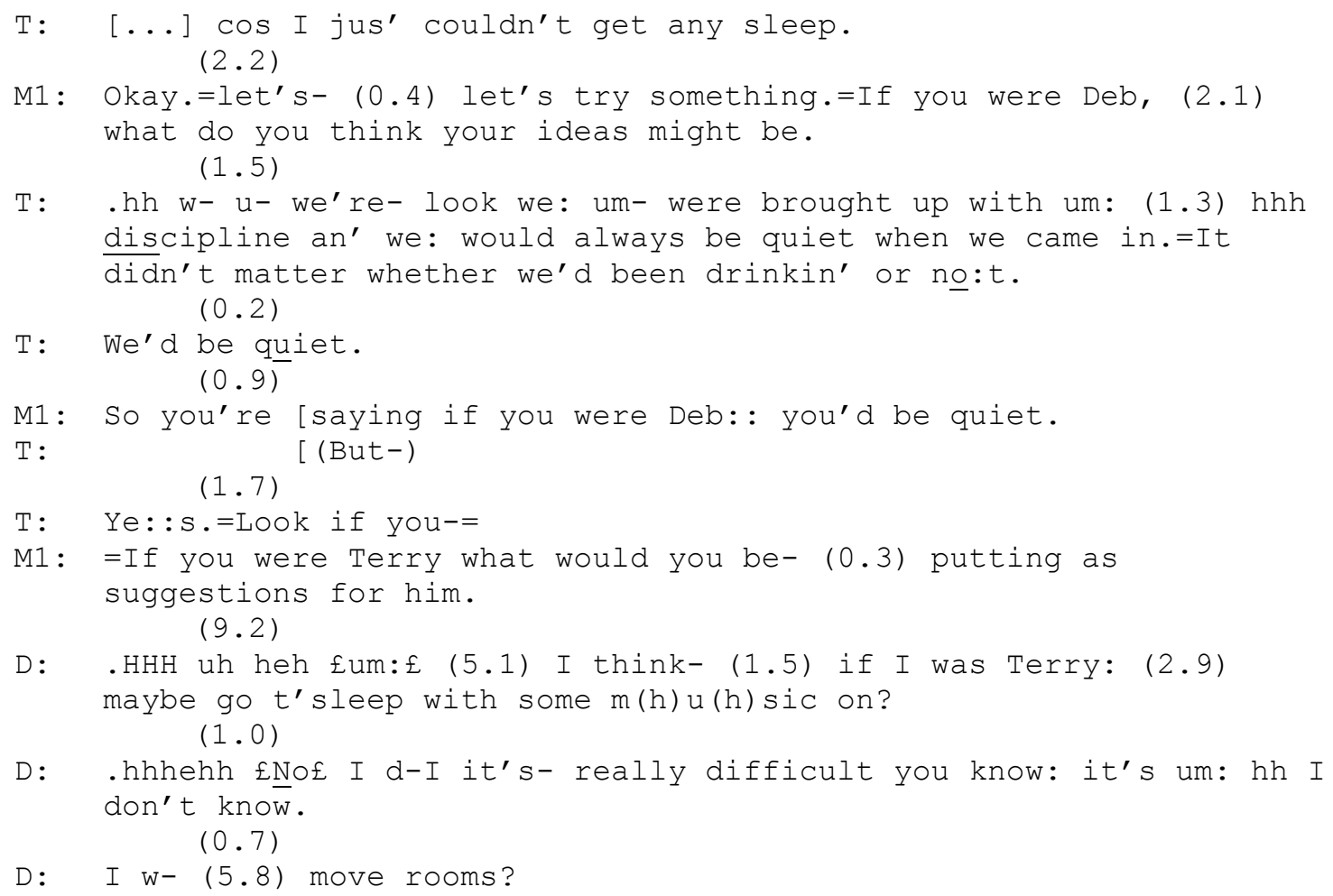

The target formulation comes at line 12, in which M1 formulates Terry's response to the SFQ at lines 3-4. But let us start with the question itself. After a long gap (line 2), M1 initiates a new sequence "Okay.=let's- (0.4) let's try something.=". This constructs an explicit boundary between the previous activity (Terry's complaining) and the new one, doing the work of mediation. The first person plural "let's" projects joint action and shared responsibility for a solution. She moves on to ask a future-oriented hypothetical question of Terry, inviting him to see things from Deb's perspective (lines 3-4; cf. Extract 3). Having drawn a line between the previous and new sequences, M1 asks Terry, "If you were Deb, (2.1) what do you think your ideas might be".

Terry's response is not fully fitted to the question; he describes what he would do to keep quiet when returning from a night out, rather than what Deb's ideas to resolve the dispute "might be". Terry's response is marked as unfitted with "look" in line 6. At line 12, 
however, M1 formulates his response as if he had responded in a fitted way, "So you're saying if you were Deb:: you'd be quiet.". At line 15, Terry responds to this yes-no question but immediately starts what is likely to be another iteration of his complaint. At line 16, however, M1 responds quickly to take another turn and poses the same hypothetical question to Deb ("If you were Terry what would you be- (0.3) putting as suggestions for him."). By asking the same question, in a similar format, to both parties, M1 embodies a fundamental principle of mediation - its impartiality. M1 shows, at this point, that each party will be treated in the same way. Unlike Terry, Deb's subsequent responses, punctuated by very long gaps (lines 18 and 25), provide possible solutions. She treats her own first suggestion, to "go t'sleep with some $\mathrm{m}(\mathrm{h}) \mathrm{u}(\mathrm{h}) \mathrm{sic}$ on?", as ironic, but the second, to "move rooms", is a more serious solution. Perhaps unsurprisingly, Terry rejects both possibilities and the issue remains unresolved. We will see what worked to produce a solution at the end of the analysis.

For now, though, let us consider another case. Extract 7 is the round table mediation for the case introduced in Extract 2. Susie, her friend Carla and daughter (also called Susie) are now present with their neighbours, married couple Diane and Paul. Diane and Paul's complaint is focused on Susie's children's noise, and the escalation of troubles since Susie's husband died. Both sides have reported that before his death, the two families were friendly neighbours. The clients have also been arguing about Susie's bonfires which, for Paul and Diane, happen too late at night. Paul and Diane want these to stop, along with the noise. 'HousingCo' is a pseudonym for the housing association that the parties are tenants of.

\section{Extract 7: NM-C261-RT}

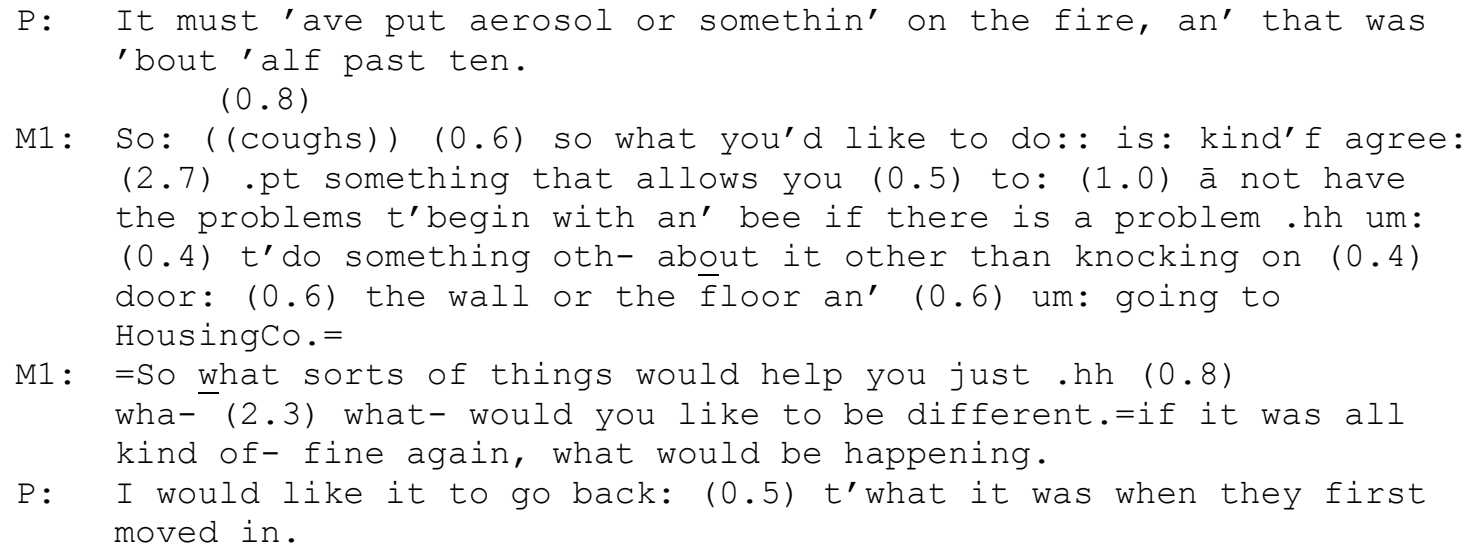

Again, the extract reveals the sequential pattern of component actions that comprise the practice we have identified: formulations appear after a period of complaining (lines 1-2); they are regularly initiated with 'so', marking a move to business - in this case a solution to 
the dispute; M1 formulates something that both parties share; the clients do not confirm the formulation (here, there is little interactional space to do so); M1 asks an SFQ (lines 10-12); she also provides and rejects candidate solutions, and then one of the clients begins to respond. Paul's solution is a return that echoes Susie's (uttered independently in a separate meeting: Extract 2) "to go back: (0.5) t'what it was when they first moved in." The formulation "so what you'd like to do:: is: ..." (lines 4-9) constructs a version of what the clients would like to 'agree' on. At this point, neither party has stated that they would like to agree anything, but have both described the things that they would like to happen. The formulation works to turn these individual descriptions into something reciprocal; something that, as we saw in earlier extracts, creates common ground between the parties.

In order to identify it clearly, we have separated the formulation from the subsequent SFQ in the transcript (lines 10-12). The SFQ is embedded in a complex turn with different components, the first of which is abandoned: "So what sorts of things would help you just .hh". Rather than ask for a list, M1 reformulates the question to a more directly built SFQ: "what- would you like to be different.=if it was all kind of- fine again, what would be happening" (lines 11-12). In response, Paul supplies an answer similar to Susie's much earlier response to M1's question, "So how would you like things to be". In the next extract, we return a few minutes later to a further iteration, in which a possible solution appears to be emerging. For the sake of space, we have omitted nine lines in which Paul begins to reiterate his complaint in response to the SFQ.

\section{Extract 8: NM-C261-RT}

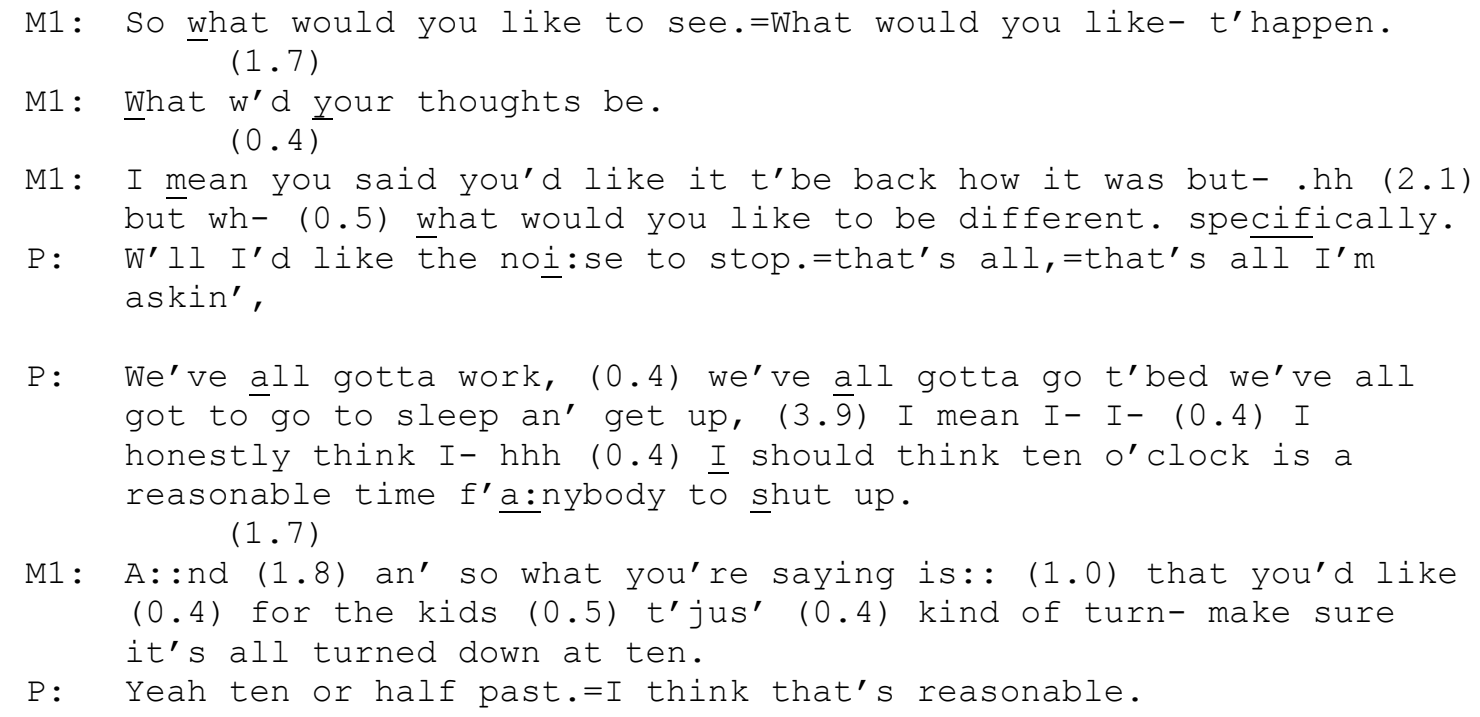


The component features are present but the SFQ initiates the sequence ("So what would you like to see."). The beginning of the SFQ is immediately reformulated ("What would you like- t'happen.") and, after a gap, M1 pursues a response ("What w'd your thoughts be."). We can see here the hypothetical nature of the SFQs, in which clients are asked what their thoughts would be and what they would like to happen. After another gap (line 4), M1 formulates part of Paul's response from Extract 7 ("I mean you said you'd like it t'be back how it was") but treats it as not sufficiently solution-focused; she asks a fourth iteration of the SFQ: "what would you like to be different. specifically." (line 6). Paul's response indeed specifies what he wants: "I'd like the noi:se to stop.", and continues to account for his response in the omitted lines and between lines 17-20. As we can see, his account for requesting a noise-free neighbour is complaint-implicative and characterizes Susie as someone who is not reasonable, if she does not "shut up" by "ten o'clock" (lines 19-20).

M1's solution to the problem of further complaining, and less solution-focused talk, is to reformulate Paul's complaint. The 'a::nd' preface, and her formulation (as a declarative, not an interrogative), is hearable as a continuation of Paul's turn, but we can see that it does work to downgrade his complaint and focus on the practical upshot that Susie can then align with or reject: "A::nd (1.8) an' so what you're saying is:: (1.0) that you'd like (0.4) for the kids (0.5) t'jus' (0.4) kind of turn- make sure it's all turned down at ten" (see also MacMartin, 2008, on optimistic questions in therapy). M1 replaces 'shut up' with 'turned down' and minimizes this as a high stakes action with 'jus'. As Bolden (2010) has shown, 'and-prefaced' formulations such as M1's "are assertions about the addressee's domain of knowledge that perform a repair operation in the form of a request for confirmation; they articulate a 'missing' element of the addressee's preceding talk (which is, typically, an extended informing turn); what is being formulated is claimably inferable from the prior talk" (p. 5). Paul does produce a confirmation that M1's formulation is correct (line 25).

The analysis above has identified component features of a robust practice that occurs in mediation sessions which are goal-oriented towards finding a solution between disputing neighbours. Although not all examples follow the precise order of actions, the iterative nature of formulation-SFQ sequences means that some other combinations occur. In general, formulations are typically preceded by parties complaining or arguing; mediators formulate either i) one party's version of, or stance towards, the dispute, or ii) something that both parties share. Formulations therefore work to mutualize the dispute ("so you both feel uncomfortable"; "we have this overlap then in lifestyles"; "what you'd like to do:: is: kind'f agree:"), such that mediators can foreground common ground between the parties as a way of bringing about movement towards solutions. Clients either confirm, reject or disattend the formulation (with the latter two actions being more typical, particularly in round tables). Next, 
mediators ask a 'future hypothetical' SFQ of the client or clients. SFQs themselves are often embedded in turns with other components such as increments or reformulations of the SFQ (Extracts 3, 4, 5, 6). We found that mediators often provide a candidate answer to their SFQ (e.g., Extracts 2, 3, 5, 7, 8), and occasionally clients provide a candidate solution (Extracts 6, 7,8 ) but, more commonly, complain further (Extracts 2, 3, 5, 6, 8) - or one party only provides a solution while the other continues to complain.

Let us revisit the parties in both round table cases to pin down the moment in which a solution becomes more concrete.

\subsection{The solution}

It is a challenge for conversation analysts working with long and complex encounters to present key moments in which discrete actions can be pinned down. The turns in which 'the solution' appears in mediation sessions are sometimes clear but sometimes opaque. However, in the examples of 'round table' mediations, what we will see is that it is mediators, not clients, who formulate solutions for clients to confirm or reject. In the case of Terry and Deb, we saw multiple, persistent iterations of Terry's noise complaint, and his resistance in providing solutions in response to SFQs, unlike Deb who did make suggestions (e.g., Extract 6). We join Extract 9 after Terry has begun to discuss 'court' and 'solicitors': solutions which are antithetical to the mediation ethos.

\section{Extract 9: NM-C252-RT}

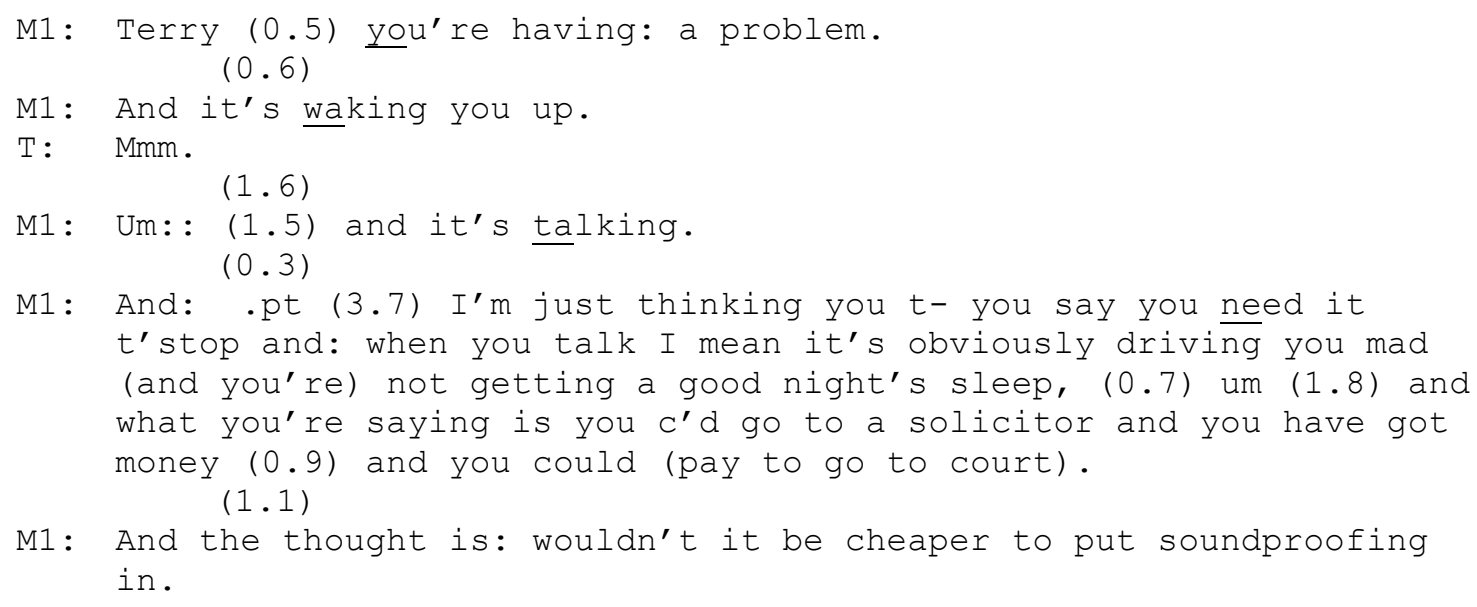

From lines 1-6, M1 formulates Terry's version of the problem. The formulation is positioned sequentially before a yes/no question which incorporates a candidate solution ("wouldn't it..." ... "put soundproofing in"; lines 14-15). The notion of soundproofing has come from M1, 
not the clients and, as such, is antithetical to the mediation process. Notice the way M1 attends to this; she describes Terry's problems, and then presents her solution as something she happened upon rather than had worked out before the mediation started ("I'm just thinking...", line 8; "and the thought is", line 14). Thus, like in Extract 8, the 'and-preface' to her solution articulates "a 'missing' element of the addressee's preceding talk" (Bolden, 2010: 5) and is built off a formulation of Terry's version of events ("what you're saying is", lines 1011).

Here, then, is the solution that the parties work with until the end of the session. The parties agree, eventually, to share the cost of soundproofing if an expert suggests strongly that this would improve the noise insulation between Terry and Deb's homes. Terry's initial resistance to this solution is gradually replaced by an alignment with it. Interestingly, it is a solution that avoids either party agreeing to change their behaviour; the problem is relocated to the material environment. While this may, indeed, be the cause of many noise disputes, it works entirely against the written practice of mediation, in mediators guide people towards agreeing to change their behaviours. However, the challenge of mediation is also that mediators are experts; professionals; consulted on how to improve relationships in situations where people have failed to resolve issues for themselves. Clients want mediators to side with them and not be impartial; to provide solutions not leave it for them to 'sort out differences' (Stokoe, 2013). The challenge of mediation can be found in formulations and solution-focused, or, here, solution-proposing questions. Solutions are the work of mediation; but they are not necessarily the work of clients.

Similar observations can be made in the other example presented, in which Susie, Diane and Paul also seek to resolve their noise problems.

\section{Extract 10: NMC261RT}

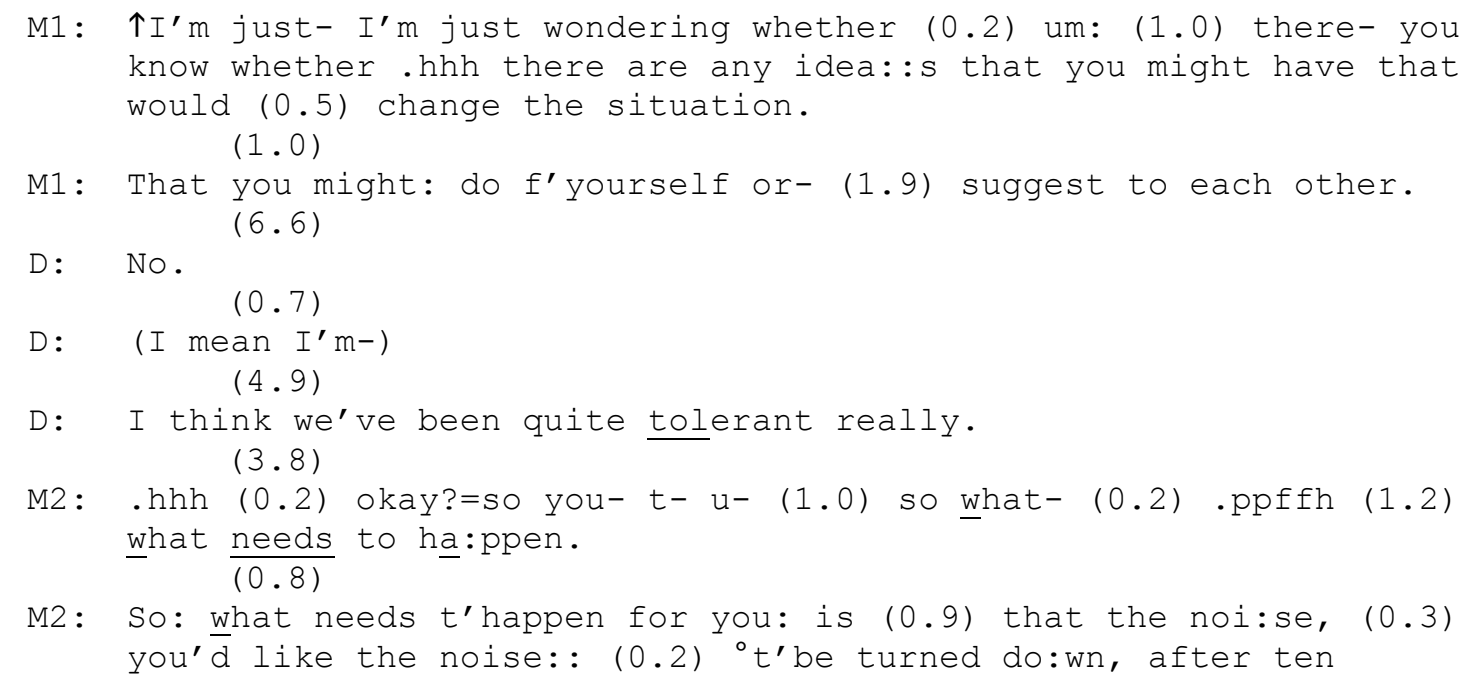




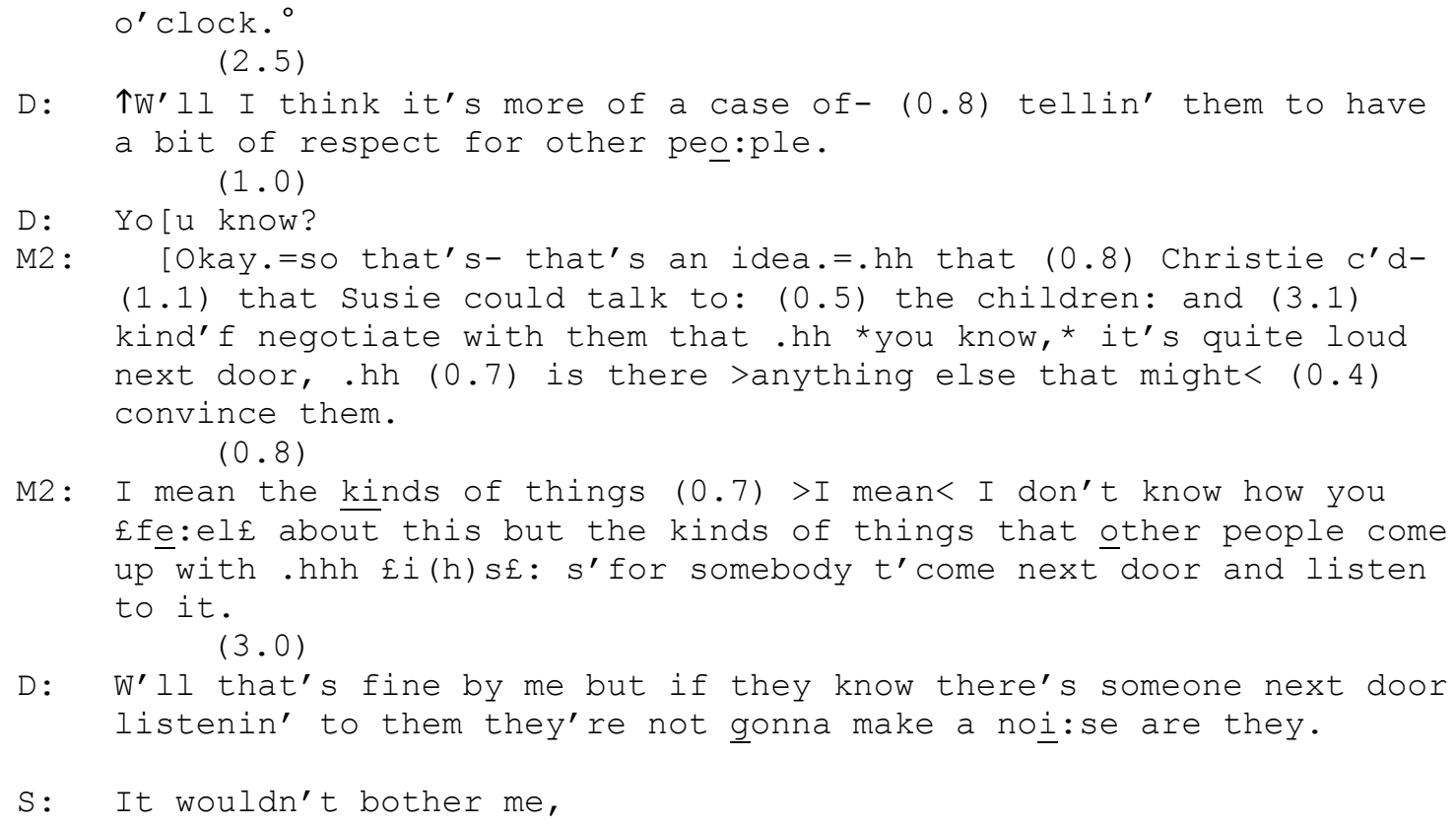

M1 constructs two SFQs: The first comes at lines 1-3 (“... are there any ideas...”), with, as we saw in previous examples, an increment (line 5). At line 7, Diane responds with a markedly dispreferred response ("No") - at least it is dispreferred in terms of the presumed function of M1's question. That said, as we saw in Extract 4, the question is built with 'any', which raises the expectations for a 'no' response. Therefore the 'no' may instead turn out to be a preferred response. Diane then supplies an account for why she has no ideas to change the situation: "I think we've been quite tolerant really."

M1's first SFQ, then, failed to generate solutions. At line 13, M2 initiates a new sequence with a second SFQ: "so what- (0.2) .ppffh (1.2) what needs to ha:ppen.". Like previous extracts, M2 uses a formulation to begin a candidate answer for Paul and Diane ("So: what needs t'happen for you: ...", line 16), suggesting their preferred solution, that the noise is "ot'be turned do:wn, after ten o'clock. .". After a long gap, marking an upcoming dispreferred response, Diane starts her turn with another dispreference marker ("well"), and proposes a more general (and less tangible) solution that Susie (and presumably her children) "have a bit of respect for other peo:ple.". After a gap, Diane pursues a response from M2 (“You know?"). Like M1, M2 responds to Diane's unproductive (in mediation terms) response with "okay", acknowledging but not affirming it, and formulating it as "an idea" (line 23).

M2 then uses her characterization of Diane's turn as "an idea" to propose a subtly different solution, but as if it had emerged from Diane herself: "Susie could talk to: (0.5) the children: and (3.1) kind'f negotiate with them ..." (lines 23-25). She uses this formulation to preface another question: "is there >anything else that might< $(0.4)$ convince them". After no 
response from the clients, M2 proposes a solution; that somebody else might "come next door and listen to it". This is not proposed as M2's personal choice of solution, however. Its preface manages and produces mediation practice that does not provide solutions but facilitates clients' own solutions: "I mean the kinds of things $(0.7)>I$ mean< I don't know how you £fe:el£ about this but the kinds of things that other people come up with”. M2's solution is therefore produced as something that other people in the clients' position have come up with; these are clients', not mediators', solutions. Although Diane's initial response is rejection-implicative, Christie's is more positive (line 41) and this solution is something that the clients eventually agree to do.

Like Extract 9, then, it is mediators' solutions, carefully managed to avoid staking a personal claim in them, but built off formulations of (actually unproductive) things that clients say, that are taken forward by the participants. In both cases, the 'complaining' parties Terry, and Diane/Paul - resist the proffered solution but eventually coalesce; the complained-about parties - Deb and Susie - are quicker to align with it. Solution-focused questions do not readily generate solutions, but they are put to use in the service of subtlydone mediator-proposed solutions, which are, in turn, built off subtly-done formulations of clients' turns at talk.

\section{CONCLUDING REMARKS}

This paper has examined the work done by formulations in the service of pursuing solutions to disputes between neighbours in a community mediation setting. Our analysis has focused on the way that mediators formulate the narratives offered by mediation clients - the parties in dispute - in a sequence of actions that provide an interactional environment for 'solutionfocused' questions (SFQ). Such questions are treated in mediation training as a key method of effecting client-generated solutions to noise and other sorts of neighbour disputes. However, while SFQs did not readily generate solutions, they were put to use in the service of subtly-done mediator-proposed solutions, which are, in turn, built off subtly-done formulations of clients' turns at talk.

Specifically, the analysis identified distinct formulation-SFQ sequences. Formulations were typically preceded by parties complaining or arguing; mediators formulated either one party's version of, or stance towards, the dispute, or propose something that both parties share. Formulations therefore work to mutualize the dispute such that mediators can foreground common ground between the parties as a way of bringing about movement towards solutions. Clients either confirm, or, more typically, reject or disattend the 
formulation. We also investigated the moments in which 'solutions' actually occurred in mediations, and how they came about. In the cases examined, it was mediators, not clients, who proposed solutions, albeit as if emerging from earlier talk from clients, or as the kinds of solutions that other clients have reached in similar mediations. Making suggestions works against the written practice of mediation, in which mediators guide people towards identifying their own solutions. However, the challenge of mediation is also that mediators are experts; professionals; consulted on how to improve relationships in situations where people have failed to resolve issues for themselves.

The paper has contributed to what we know about the institutional uses of formulations and how they work to accomplish the goals of an organization. When compared to other institutional uses of formulations, we have seen that mediators use formulations to be accountably non-directive (cf. Fitzgerald and Leudar, 2012) while simultaneously steering clients towards solutions. Mediators formulate the gist of prior talk in terms of clients' experiences or stances towards their dispute (Heritage and Watson, 1979) and orient them towards future actions (Gafaranga and Britten, 2004). However, as we have seen, mediators use formulations to precede another action that functions to get clients to commit to changing their behaviour: the SFQ. Formulations are at the heart of the mediation process, in which mediators attempt to scaffold clients to come to an agreement about ways to move forward, but without giving direct instruction or advice. Mediation's particular constraints and ideology can be found in these sequences. Solutions are the work of mediation; but they are not necessarily the direct work of clients. The overriding challenge of mediation can be found, therefore, in the iterative practice of formulation-SFQ sequences.

\section{ACKNOWLEDGMENT}

The data were collected as part of ESRC grant number RES-148-25-0010 "Identities in neighbour discourse: Community, conflict and exclusion", held by Elizabeth Stokoe and Derek Edwards.

\section{REFERENCES}

Alberts, Jess K., Heisterkamp, Brian L., McPhee, Robert M., 2005. Disputant perceptions of and satisfaction with a community mediation program. International Journal of Conflict Management 16 (3), 218-244. 
Bolden, Galina B., 2010. 'Articulating the unsaid' via and- prefaced formulations of others' talk. Discourse Studies 12 (1), 5-32.

Bolden, Galina B., 2009. Implementing incipient actions: The discourse marker 'so'. Journal of Pragmatics

Bolden, Galina B., 2008. "So what's Up?": Using the Discourse Marker So to Launch Conversational Business. Research on Language and Social Interaction 41 (3), 302-337.

Bowles, Nick, Mackintosh, Carolyn, Torn, Alison, 2001. Nurses' communication skills: an evaluation of the impact of solution- focused communication training. Journal of Advanced Nursing 36 (3), 347-354.

Charkoudian, Lorig, 2010. Giving police and courts a break: the effect of community mediation on decreasing the use of police and court resources. Conflict Resolution Quarterly 28 (2), 141-155.

de Shazer, Steve, 1994. Words were Originally Magic. New York: Norton.

Edwards, Derek, 1995. Two to tango: Formulations, dispositions, and rhetorical symmetry in relationship troubles talk. Research on Language and Social Interaction 28 (4), 319-350.

Fitzgerald, Pamela, Leudar, Ivan, 2012. On the use of formulations in person-centred, solution-focused short-term psychotherapy. Communication \& Medicine 9 (1), 13-22.

Gafaranga, Joseph, Britten, Nicky, 2004. Formulation in general practice consultations. Text: An Interdisciplinary Journal for the Study of Discourse 24 (2), 147-170.

Gale, Jerry, Newfield, Neal, 1992. A Conversation Analysis of a solution- focused marital therapy session. Journal of Marital and Family Therapy 18 (2), 153-65.

Glenn, Phillip, Susskind, Lawrence, 2010. How talk works: studying negotiation interaction. Negotiation Journal 26 (2), 117-123.

Goldberg, Stephen B., 2005. The secrets of successful mediators. Negotiation Journal 21 (3), 365-376.

Greatbatch, David, Dingwall, Robert, 1997. Argumentative talk in divorce mediation sessions. American Sociological Review 62 (1), 151-170. 
Heritage, John, 1985. Analyzing news interviews: aspects of the production of talk for an overhearing audience. In: Dijk, T.A.v. (Ed.), Handbook of Discourse Analysis: Discourse and Dialogue, vol. 3, Academic Press, London, pp. XIX, 251.

Heritage, John, Watson, Rod, 1979. Formulations as conversational objects. In: Psathas, G. (Ed.), Everyday Language: Studies in Ethnomethodology. New York: Irvington Press, pp. 123-162.

Heritage, John, Robinson, Jeffrey D., Elliott, Marc N., Beckett, Megan, Wilkes, Michael, 2007. Reducing patients' unmet concerns in primary care: the difference one word can make. Journal of General Internal Medicine 22 (10), 1429-1433.

Houtkoop-Steenstra, Hanneke, Antaki, Charles, 1997. Creating happy people by asking yesno questions. Research on Language and Social Interaction 30 (4), 285-313.

Jacobs, Scott, Aakhus, Mark, 2002. What mediators do with words: implementing three models of rational discussion in dispute mediation. Conflict Resolution Quarterly 20 (2), 177-203.

Jefferson, Gail, 2004. Glossary of transcript symbols with an introduction. In: Lerner, G. H. (Ed.), Conversation Analysis: Studies from the First Generation. Amsterdam/Philadelphia: John Benjamins, pp. 13-31.

MacMartin, Clare, 2008. Resisting optimistic questions in narrative and solution-focused therapies'. In: Anssi Peräkylä, Charles Antaki, Sanna Vehviläinen, Ivan Leudar (Eds.), Conversation Analysis and Psychotherapy. Cambridge: Cambridge University Press, pp. 80-99.

Maynard, Douglas W., Scaeffer, Nora C., 2006. Standardization-in-interaction: the survey interview. In: Drew, P., Raymond, G., Weinberg, D. (Eds.), Talk and Interaction in Social Research Methods. London, England: Sage, pp. 9-27.

Molnar, Alex, de Shazer, Steve, 1987. Solution-focused therapy: toward the identification of therapeutic tasks. Journal of Marital and Family Therapy 13 (4), 349-358.

Schegloff, Emanual A., Lerner, Gene H. 2009. Beginning to respond: Well-prefaced responses to Wh-questions. Research on Language and Social Interaction 42 (2), 91 115. 
Stokoe, Elizabeth, 2013. The (in)authenticity of simulated talk: comparing role-played and actual interaction and the implications for communication training. Research on Language and Social Interaction 46 (2), 165-185.

Stokoe, Elizabeth, 2006. Public intimacy in neighbour relationships and complaints. Sociological Research Online 11 (3).

Stokoe, Elizabeth, Edwards, Derek, 2009. Accomplishing social action with identity categories: mediating neighbour complaints. In: Wetherell, M. (Ed.), Theorizing Identities and Social Action. London, England: Sage, pp. 95-115.

Trinder, Liz, Firth, Alan, Jenks, Christopher, 2010. 'So presumably things have moved on since then?' the management of risk allegations in child contact dispute resolution. International Journal of Law, Policy and the Family 24 (1), 29-53.

van der Houwen, Fleur, 2008. Formulating disputes. Journal of Pragmatics, 41 (10), 20722085.

Wall, James Allen, Dunne, Timothy C., Chan-Serafin, Suzanne, 2011. The effects of neutral, evaluative, and pressing mediator strategies. Conflict Resolution Quarterly 29 (2), 127 150.

Weatherall, Ann, 2015. "But whose side are you on?" Doing being idependent in telephonemediated dispute resolution. In Fabienne H.G. Chevalier \& John Moore (Ed.), Producing and managing restricted activities. Amsterdam: John Benjamins. Pp. 151-180.

Wells, Bill, Macfarlane, Sarah, 1998. Prosody as an interactional resource: Turn-projection and overlap. Language and Speech 41 (3), 265-294. 